\title{
An attenuated Lassa vaccine in SIV-infected rhesus macaques does not persist or cause arenavirus disease but does elicit Lassa virus-specific immunity
}

Juan C Zapata', Bhawna Poonia', Joseph Bryant ${ }^{1}$, Harry Davis ${ }^{1}$, Eugene Ateh ${ }^{1}$, Lanea George ${ }^{1}$, Oswald Crasta ${ }^{2}$, Yan Zhang ${ }^{2}$, Tom Slezak ${ }^{3}$, Crystal Jaing ${ }^{3}$, C David Pauza', Marco Goicochea', Dmitry Moshkoff', Igor S Lukashevich ${ }^{1,4}$ and Maria S Salvato ${ }^{1 *}$

\begin{abstract}
Background: Lassa hemorrhagic fever (LHF) is a rodent-borne viral disease that can be fatal for human beings. In this study, an attenuated Lassa vaccine candidate, ML29, was tested in SIV-infected rhesus macaques for its ability to elicit immune responses without instigating signs pathognomonic for arenavirus disease. ML29 is a reassortant between Lassa and Mopeia viruses that causes a transient infection in non-human primates and confers sterilizing protection from lethal Lassa viral challenge. However, since the LHF endemic area of West Africa also has high HIV seroprevalence, it is important to determine whether vaccination could be safe in the context of HIV infection.

Results: SIV-infected and uninfected rhesus macaques were vaccinated with the ML29 virus and monitored for specific humoral and cellular immune responses, as well as for classical and non-classical signs of arenavirus disease. Classical disease signs included viremia, rash, respiratory distress, malaise, high liver enzyme levels, and virus invasion of the central nervous system. Non-classical signs, derived from profiling the blood transcriptome of virulent and non-virulent arenavirus infections, included increased expression of interferon-stimulated genes (ISG) and decreased expression of COX2, IL-1 $\beta$, coagulation intermediates and nuclear receptors needed for stress signaling. All vaccinated monkeys showed ML29-specific antibody responses and ML29-specific cellmediated immunity.
\end{abstract}

Conclusion: SIV-infected and uninfected rhesus macaques responded similarly to ML29 vaccination, and none developed chronic arenavirus infection. Importantly, none of the macaques developed signs, classical or nonclassical, of arenavirus disease.

Keywords: Lassa fever virus, Vaccine, Macaque, SIV-infected, Genomic profiling, Disease markers

\footnotetext{
* Correspondence: msalvato@ihv.umaryland.edu

${ }^{1}$ Institute of Human Virology, University of Maryland School of Medicine, 725

West Lombard Street, Baltimore, MD 21201, USA

Full list of author information is available at the end of the article
} 


\section{Background}

Lassa hemorrhagic fever (LHF) is a rodent-transmitted disease that causes more than 300,000 human cases per year in the West African endemic area. Mortality rates are between $15-20 \%$ in hospitalized individuals, and reach $50 \%$ in epidemic episodes [1,2]. Those who develop effective antiviral immunity survive, while those with uncontrolled high viral loads succumb [3-5]. Lassa virus (LASV) replicates in almost all human tissues with the highest titers being found in liver and secondary lymphoid organs. However, the extent of tissue damage is not enough to implicate the failure of any one organ as the cause of death $[1,6]$. Besides viremia, other signs of LHF include myocarditis, pulmonary edema, and in advanced cases, hemorrhage and hypovolemic shock resulting from vascular leakage [6]. Due to the undifferentiated symptoms at the onset of LHF, the opportunity to administer ribavirin treatment is often missed; so the best public health option in endemic areas would be vaccination.

Many LHF vaccines have shown promise in small animal models: viral sub-particles, peptides, DNA vaccines and viral vectors [7]. The most effective candidates have been attenuated vectors that protected against LASV challenge in primate models: vaccinia virus expressing LASV glycoprotein (GP) and nucleocapsid protein (NP) [8], vesicular stomatitis virus expressing LASV GP [9], and the ML29 reassortant vaccine expressing the GP and NP of LASV and the $\mathrm{Z}$ and L proteins of Mopeia virus (MOPV) [10-13]. A yellow fever vaccine, YF17D, expressing LASV GP (YF-LASV-GP) was protective in guinea pigs [14] but not in primates (ISL unpublished). ML29 is the only Lassa vaccine candidate that elicited strong cell-mediated immunity before challenge and that provided sterilizing immunity in several animal models [7,10-13]. For all the live attenuated vectors, safety concerns remain to be addressed before launching clinical trials.

One safety concern is that the Lassa endemic region of West Africa has high seroprevalence for infection with Human Immunodeficiency Virus-1 (HIV): 5-12\% of young adults are HIV positive [15] with most of these individuals being unaware that they are HIV-infected. Several vaccine studies have attempted to model vaccination of HIV-infected individuals by delivering attenuated vaccines to immune-deficient animals: a Rift Valley Fever vaccine was given to immune-deficient mice [16], an Ebola vaccine (VSV-EBOGP) was given to SHIVinfected monkeys [17], and a smallpox vaccine was given to SIV-infected monkeys [18]. Two of these studies selected viremic monkeys with low CD4 counts. Monkeys for our study had been infected with a pathogenic stock of SIVmac251, and vaccinated with VSVgag that doubles the ordinarily one-year lifespans of SIV-infected macaques [19], thereby prolonging the time available for the study.

The Mopeia/Lassa (ML29) reassortant virus used in this study can be an effective, broadly cross-reactive Lassa vaccine $[7,11,20,21]$. The large $(\mathrm{L})$ genomic segment of ML29 is derived from the mild MOPV [22-25]. The S segment of ML29 encodes the NP and GP gene products derived from LASV [10-13,26,27]. ML29 appears to be even more attenuated than its parental MOPV both in vitro and in vivo $[10,11]$.

In this study, we employed SIV-infected macaques as a model for persons living with HIV. Our goal was to determine whether ML29 is safe and immunogenic in macaques during advanced stages of SIV-infection.

\section{Results}

Rhesus macaque survival and viral loads

The experimental plan is diagrammed in Figure 1. Briefly, 393 days after infection with SIVmac251, eleven rhesus macaques were enrolled in this study. Eight macaques were inoculated with an attenuated LASV vaccine ML-29, in order to determine whether they could still elicit LASVspecific immune responses without developing signs of arenavirus disease. Five of the 8 were given ML29 subcutaneously (s.c.) and 3 were given ML29 intragastrically (i.g.). Both routes were successful, but the i.g. route required a higher dose [28]. Three additional SIV-infected macaques were inoculated with LCMV-Armstrong known from previous studies to cause a brief, uneventful infection in SIV-infected monkeys (MSS and JCZ unpublished). As controls, 5 healthy non-SIV-infected rhesus macaques were vaccinated s.c. with ML29.

SIV-positive animals were classified as slow, median or rapid progressors based on their physical signs and SIV viral loads at set point, i.e. 3 months after infection (Table 1, Figure 2A, B, and C). Seven of the 8 SIV/ML29 monkeys experienced a drop in SIV titers (median 20\%) during the first week after ML29 inoculation, but those titers returned the following week (Figure 2D).

Two rapid-progressors were euthanized on days 34 and 63 and two median progressors were euthanized on days 57 and 105 after ML29 vaccination (Table 1, Figures 2 and 3). The first euthanized animal (SIV/ML3) had high SIV loads and wasted appearance prior to ML29 vaccination. This animal developed a barelydetectable ML29 viremia ( $10^{3} \mathrm{pfu} / \mathrm{ml}$ of plasma) 3 weeks after vaccination. (This titer of $10^{3} \mathrm{pfu} M L 29 / \mathrm{ml}$ is still below the $>10^{4} \mathrm{pfu} / \mathrm{ml}$ considered to be a disease sign related to poor prognosis in LHF). Transient ML29 viremia (80 pfu/ml of plasma) was also detected one week after vaccination in the second euthanized monkey (SIV/ML-1), and in a long-term surviving monkey (SIV/ ML-8 had $20 \mathrm{pfu} / \mathrm{ml}$ plasma) 3 weeks after vaccination (Figure 4). 

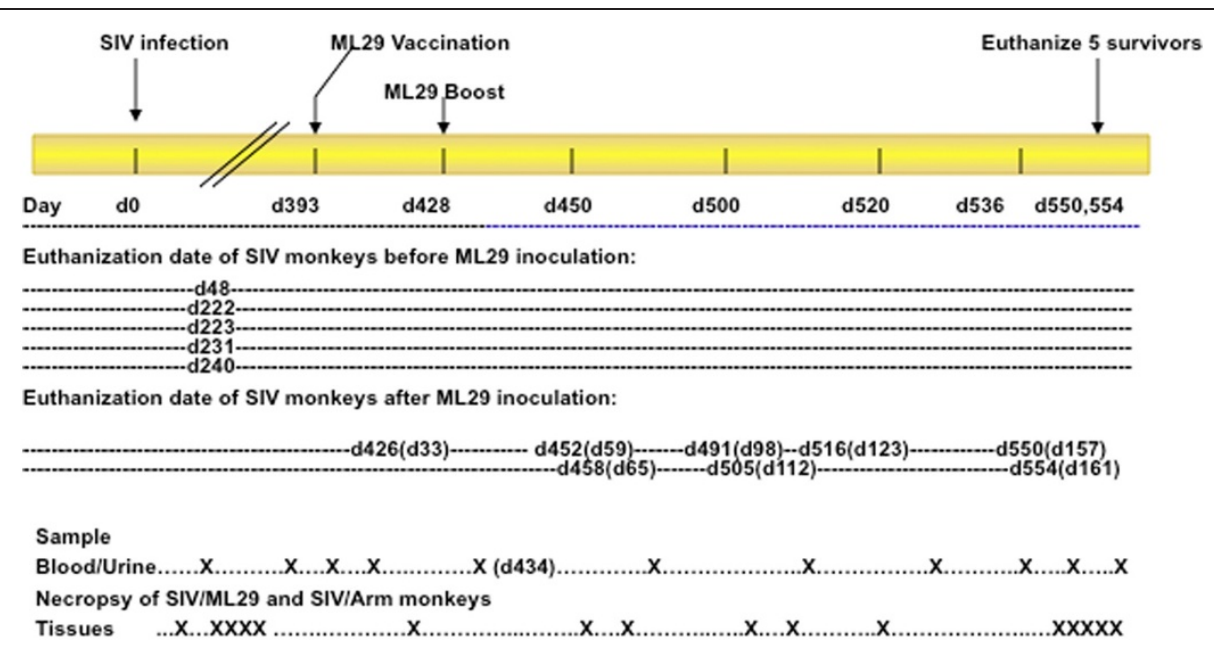

Figure 1 Experimental design. Sixteen rhesus macaques were inoculated with SIVmac251 and monitored for viral loads and SIV-specific immunity. Five succumbed within a year after SIV inoculation (48, 222, 223, 231, and 240 days after SIV infection) and the remaining 11 monkeys were vaccinated with ML29 or LCMV-Armstrong on day 393 after SIV-infection. A month after the vaccination, five monkeys (ML-1, SIV/ML-1, SIV/ ML-2, SIV/ML-6, SIV/ML-7) were boosted with ML29. Necropsies for 6 animals were performed on days 426, 452, 458, 491, 505, and 516 (after SIV). Five months after ML29 vaccination, 5 animals were still surviving. $(X)$ indicates the relative position on the timeline of samplings and necropsies.

ML29 plasma viremia was measurable by conventional plaque assay in 3 of 8 SIV-infected monkeys but not in non-SIV-infected monkeys (Table 1). When ML29 was not detectable by direct plaque assay or by RT-PCR, it could sometimes be detected by a 2-step amplification in which plasma or "infected" cells were co-cultured with Vero cells, then the media was harvested and subjected to conventional plaque assay. By this sensitive assay, ML29 was detected in plasma of 2 of 5 non-SIV-infected monkeys (ML-3 at week 1 and ML4-at week 2 after ML29 vaccination). Solid tissues of ML29-vaccinated monkeys (spleen, LN, brain, liver, kidney, heart, lung, adrenals) were all negative for ML29 by direct plaque assays.

Urine samples were collected from the monkeys weekly and assessed for virus shedding. Only two of the monkeys (SIV/ML-7 and SIV/ML-6) had detectable virus in urine during weeks two and three after ML29 inoculation respectively. The shed virus was not ML29 by plaque morphology or by detection arrays [29] which showed it to be Adenovirus 52, a virus that has been isolated previously from zookeepers [30,31] and can cause subclinical infection in non-human primates [32].

\section{Rationale for euthanizing animals in these studies}

All four of the earliest-euthanized SIV-infected animals had wasting that began prior to ML29-inoculation. Upon necropsy it was evident they also had swollen ileo-caecal lymph nodes that are a hallmark of terminal AIDS [33]. Five of the original 16 SIV-infected monkeys died of AIDS prior to the onset of the ML29 vaccinations, and the time to death of the 11 remaining monkeys was not detectably influenced by the ML29 vaccination. Two major signs of virulent arenavirus disease and more specifically of lethal Lassa fever are high levels of liver enzymes and petechiae [6]. None of the ML29-vaccinated animals in this study showed high liver enzyme levels. All hematological and chemical parameters [urine analysis (BUN, creatinine), blood chemistry (glucose, cholesterol), blood cell counts, hematocrit, and erythrocyte sedimentation] were within normal ranges and no macaques developed clinical manifestations of arenavirus disease. This absence of arenavirus-specific pathology resembles previous ML29 trials in monkeys, marmosets and guinea pigs $[10,12,13]$.

At the end of this study, approximately 5 months after the first ML29 vaccination, 5 animals (SIV/ML-2, SIV/ ML-4, SIVML-5, SIV/ML-8, SIV/ARM-2) were still healthy, never having shown signs of arenavirus disease.

\section{ML29-specific humoral and cellular immune responses}

In previous work we reported that rhesus macaques infected with the lethal LCMV-WE and non-pathogenic LCMV-Armstrong showed a drop in circulating NK and $\gamma \delta \mathrm{T}$ cells, indicating that this is not a disease-specific event but instead infection-associated lymphopenia [34]. In agreement with this work, the analysis of blood cell subsets, in both SIV-infected and non-infected controls, showed a decrease in percentage of circulating NK $(\mathrm{CD} 16+)$ cells a week after vaccination (Figure 5A and B). The CD14+ (monocyte) population showed a modest increase in the SIV-infected group and a marked increase in the control group one week after ML29 vaccination (Figure 5C and D).

Anti-LASV IgG antibodies were detected by ELISA from weeks 1 to week 5 and then monthly until the time 
Table 1 Immune responses and viremia in SIV/ML29-infected monkeys and controls

\begin{tabular}{|c|c|c|c|c|c|}
\hline Animal ID & $\begin{array}{l}\text { Cell-mediated immunity } \\
\text { (IFN } \gamma \text { response) } 1 \text { week } \\
\text { after vaccination }{ }^{b}\end{array}$ & $\begin{array}{l}\text { Antibody } \\
\text { response }^{c}\end{array}$ & $\begin{array}{l}\text { Plasma } \\
\text { Viremia }^{d}\end{array}$ & $\begin{array}{l}\text { Time of euthanasia } \\
\text { after ML29 }\end{array}$ & $\begin{array}{l}\text { SIV viral load } \\
\text { at set point }\end{array}$ \\
\hline SIV/ML-1 SC ${ }^{\mathrm{a}}$ & ++++ & ++++ & $80 \mathrm{pfu} / \mathrm{ml}$ & Week 8 & (M) $10^{5}-10^{6}$ \\
\hline SIV/ML-2 sc & ++ & ++++ & - & $>20$ wks & (S) $10^{3}-10^{4}$ \\
\hline SIV/ML-3 sC & ++ & +++ & $1000 \mathrm{pfu} / \mathrm{ml}$ & Week 4 & (R) $10^{7}-10^{8}$ \\
\hline SIV/ML-4 SC & ++ & ++++ & - & $>20$ wks & (M) $10^{5}-10^{6}$ \\
\hline SIV/ML-5 SC & +++ & +++ & - & $>20$ wks & (S) $10^{4}-10^{5}$ \\
\hline SIV/ML-6 ig & +++++ & - - & - - & Week 14 & (M) $10^{5}-10^{6}$ \\
\hline SIV/ML-7 ig & - - & - - & - & Week 19 & (M) $10^{5}$ \\
\hline SIV/ML-8 ig & +++ & -— & $20 \mathrm{pfu} / \mathrm{ml}$ & $>20$ wks & (M) $10^{5}-10^{6}$ \\
\hline SIV/ARM-1 SC & ++ & ++ & - - & Week 16 & (R) $10^{7}$ \\
\hline SIV/ARM-2 SC & ++ & ++++ & - & $>20$ wks & (S) $10^{4}$ \\
\hline SIV/ARM-3 SC & +++ & +++ & -— & Week 9 & (R) $10^{6}-10^{7}$ \\
\hline ML-1 sc & +++ & ++++ & - & $>20$ wks & - - \\
\hline ML-2 sc & +++ & +++ & - & $>20$ wks & -— \\
\hline ML-3 sC & ++ & +++ & + & $>20$ wks & - \\
\hline$M L-4$ SC & +++ & +++ & + & $>20$ wks & - \\
\hline ML-5 SC & ++ & +++ & - & $>20$ wks & - \\
\hline
\end{tabular}

a SIV/ML-1 to SIV/ML-5 are macaques that were SIV-infected, then 393 days later, they were ML29-infected via a subcutaneous (sc) route. SIV/ML-6 to 8 were similarly SIV-infected, but then vaccinated with ML29 by an intragastric (ig) route. SIV/ARM-1 to 3 were SIV-infected and inoculated over a year later with LCMVArmstrong by the subcutaneous route. Monkeys ML-1 through ML-5 were never SIV-infected and were all inoculated SC with ML29 only.

b IFNy responses for $8 \mathrm{SIV} / \mathrm{ML}$ animals, SIV/ARM animals and 5 ML29-vaccinated animals were followed up to 22 weeks. Primary arenavirus-specific responses were measured by IFNy intracellular staining: maximum staining (+++++) corresponds to $0.4 \%$ of CD $8+$ cells, and minimum staining (+) corresponds to $0.012 \%$. Since staining was negligible for CD4+ lymphocytes, measurements are only shown for CD8+ lymphocytes. (- - -) means non-detectable.

${ }^{c}$ Arenavirus-specific antibody responses were measured by ELISA. The minimum and maximum optical density readings at $450 \mathrm{~nm}$ were 1.2 and 2.9 at $1: 100$ dilution, respectively. OD higher than 0.5 was considered positive.

${ }^{\mathrm{d}}$ Viremia in plasma of $3 \mathrm{ML} 29$-vaccinated animals refers to the transient presence of infectious ML29 particles detected by conventional plaque assay. By sensitive 2-step co-cultivation assays, none of the other SIV-infected animals had detectable ML29 in plasma or urine. (+) in two non-SIV-infected monkeys means the plasma of these animals had co-cultivation-detectable ML29 in plasma (week 1 for ML-3 and week 2 for ML-4).

e Time of euthanasia for those animals that lost more that $10 \%$ of body weight.

f SIV viral loads. Animals were classified as Rapid AIDS progressors (R) with $>10^{6}$ viral particles $/ \mathrm{ml}$; Medium, (M) between $10^{5}-10^{6}$ viral particles $/ \mathrm{ml}$; and Slow (S) with $<10^{5}$ viral particles $/ \mathrm{ml}$.

of death. All animals showed good titers of anti-Lassa IgG except for those 3 given ML29 by the i.g. route. Optical densities $\left(\mathrm{OD}_{450}\right)$ were observed to be higher than 1.25 for a 1:100 plasma dilution, when compared with negative controls at $0.30 \mathrm{OD}_{450}$ (Table 1 ).

Cell-mediated immunity is believed to mediate LASV clearance from blood and tissues of immunized animals. Previously, we showed that a single s.c. ML29 immunization of rhesus macaques induced robust cellmediated immune responses detectable in peripheral blood as early as 7 days after immunization [10]. Here the ML29-specific immune responses were measured by intracellular staining flow cytometry (ICS) for gammainterferon (IFN $\gamma$ ) and confirmed by IFN $\gamma$ ELISpot. High cell mediated immunity $(++++)$ means that $0.4 \%$ of CD8+ $\mathrm{T}$ cells stained with intracellular IFNY or that ELISpot levels exceded 200 positive cells per $10^{6}$. Low cell mediated immunity $(+)$ means that $0.012 \%$ of CD8+ T cells stained with intracellular IFNY or that ELISpot levels were less than 100 positive cells per $10^{6}$. All 5 control animals and seven of the 8 SIV-infected vaccinees had vigorous ML29-specific cell-mediated immunity by the first week after vaccination (Table 1). The animal with no ML29-specific cell-mediated response, (SIV/ML-7), also failed to produce anti-LASV IgG antibodies and survived 19 weeks after ML29 vaccination. When SIV/ML-7 finally succumbed, at a time consistent with median progression, it displayed the swollen ileo-caecal lymph nodes and increased SIV titer associated with AIDS [33]. Neither the ML-29 vaccine virus nor arenavirus disease symptoms were detected in SIV/ML-7. For those animals that survived longer than 16 weeks after ML29 vaccination, vaccine-specific cell-mediated immune responses lasted at least 18 weeks. The study was not designed to compare the longevity of immunity between SIV-infected and nonSIV-infected animals. Overall, cell-mediated immune responses were comparable in both groups although more variable in the SIV-infected monkeys. 


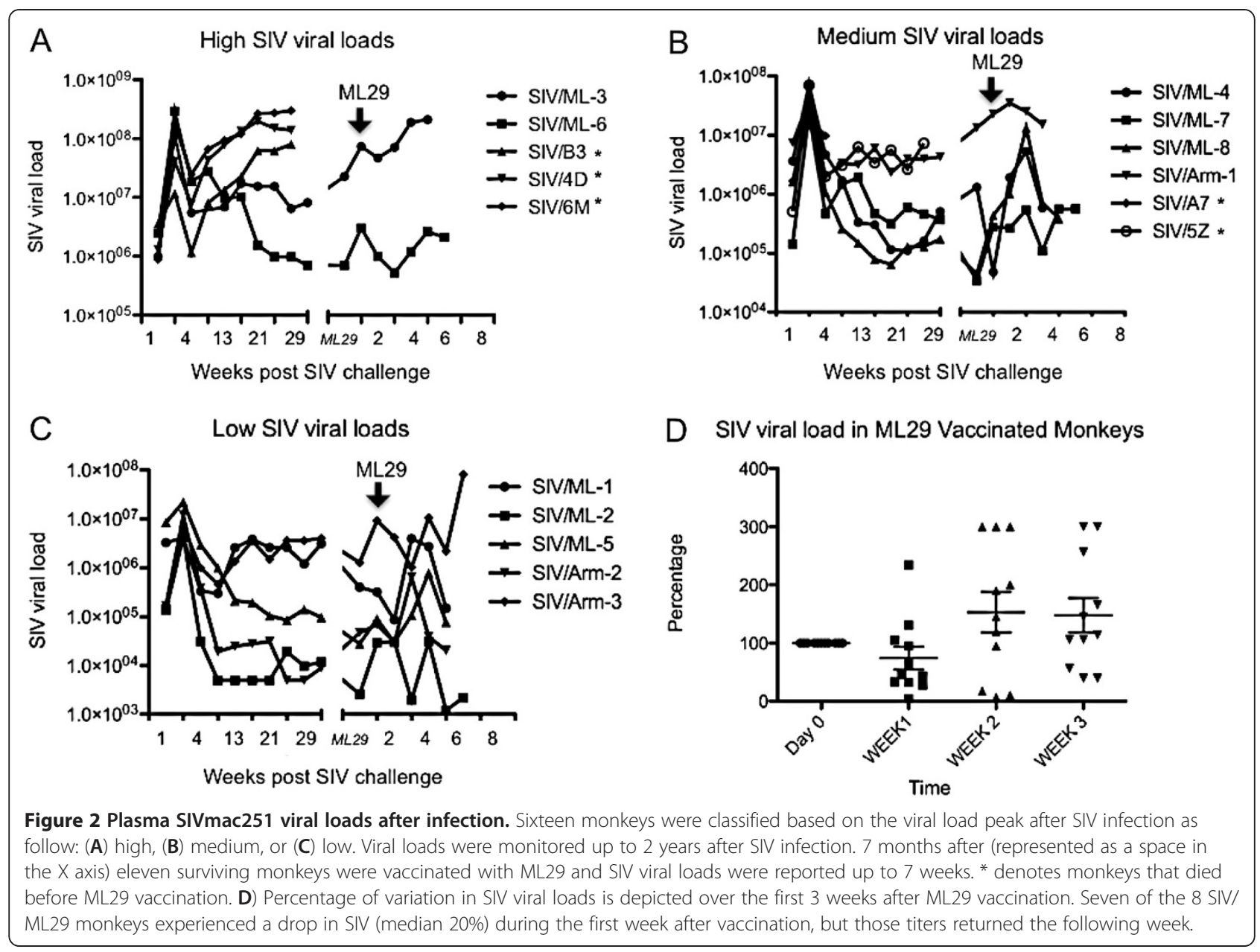

RNA profiling results

PBMC RNA was extracted 1 week after vaccination from SIV-infected and non-SIV-infected animals. Gene expression in macaque PBMC was determined by hybridization to Affymetrix microarrays as described in Methods. Approximately 100 genes were more than 2 -fold differentially expressed in SIV/ML29-infected animals with respect to SIV-infection alone. The differentially-expressed genes were compared with our previously-published RNA profiles from LCMV-WE and LCMV-ARM infections in monkeys [35], that incidentally agree with RNA profiles of guinea pig infections with virulent and benign virus pairs [36-38]. We identified 8 genes: OAS1, IFI27, SERPIN B1, IL-1B, NR4A2, PTGS2 (the gene expressing cyclooxygenase 2), IL-8, and CXCL10 (the gene for cytokine IP-10) with potential to serve as virulence markers for Lassa-like arenavirus disease. The expression of these genes in the ML29-infected monkeys was more similar to their expression in non-pathogenic LCMV-Armstrong-infected monkeys than to their expression in LCMV-WE-infected monkeys that developed a Lassa-like disease (Figure 6).

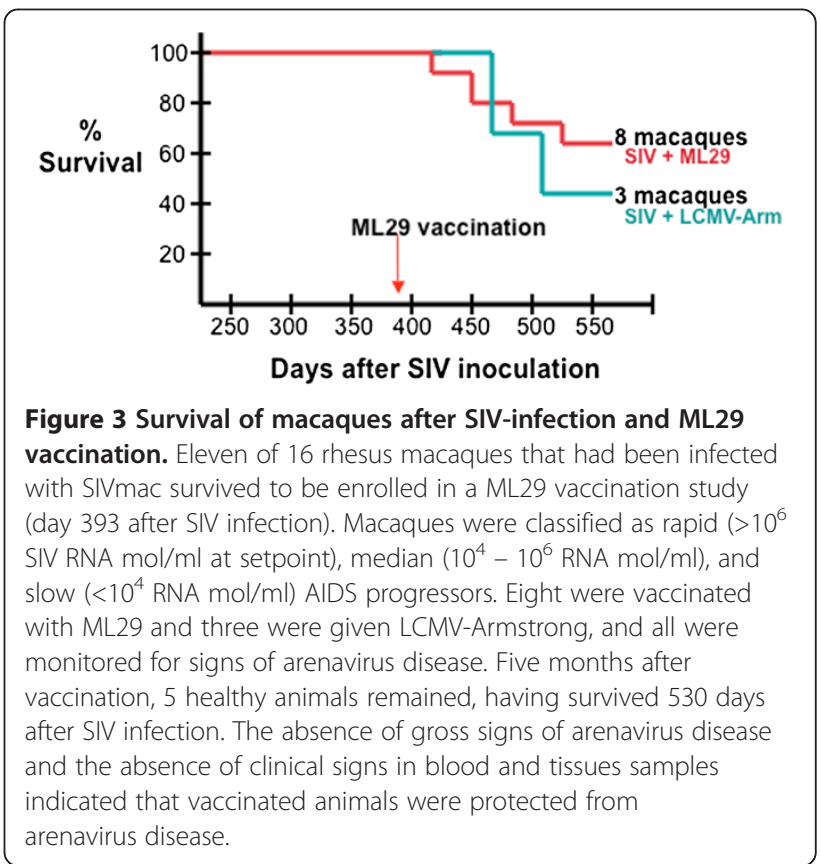




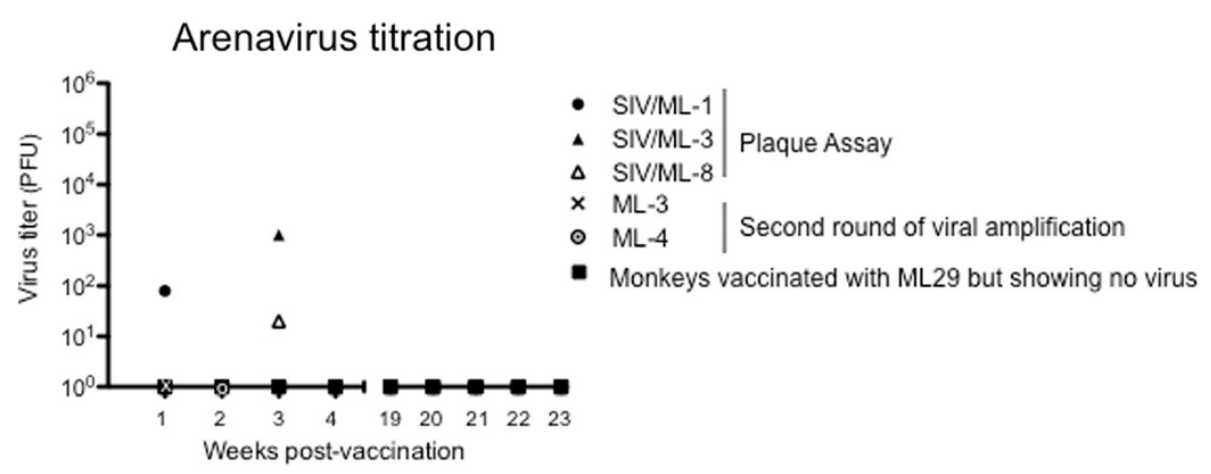

Figure 4 Detection of arenavirus in ML29-inoculated macaques. Virus titration by plaque assay revealed that only three animals (SIV/ML-1 • SIV/ML-3 $\Delta$, and SIV/ML-8 $\Delta$ ) showed low viremia by week 3 after inoculation with ML29. Negative samples were tested by a second round of amplification (see Methods), showing traces of virus in two animals (ML-3 $\times$ and ML-4 $\odot$ ), the remaining animals $(\cdot)$ tested negative until the end of the study.

\section{Discussion}

The two goals of this study were first, to determine whether ML29 infection can be virulent or persistent during co-infection with SIV, and second, to determine whether ML29 is capable of eliciting robust Lassa-specific immunity in SIV-infected primates. In Lassa fever and in virulent LCMV-WE infection, viremia greater than $10^{4}$ $\mathrm{pfu} / \mathrm{ml}$ plasma is correlated with bad prognosis [39,40]. Here, none of the ML29-vaccinated animals developed viremia greater than $10^{3} \mathrm{pfu} / \mathrm{ml}$ plasma. Nevertheless,
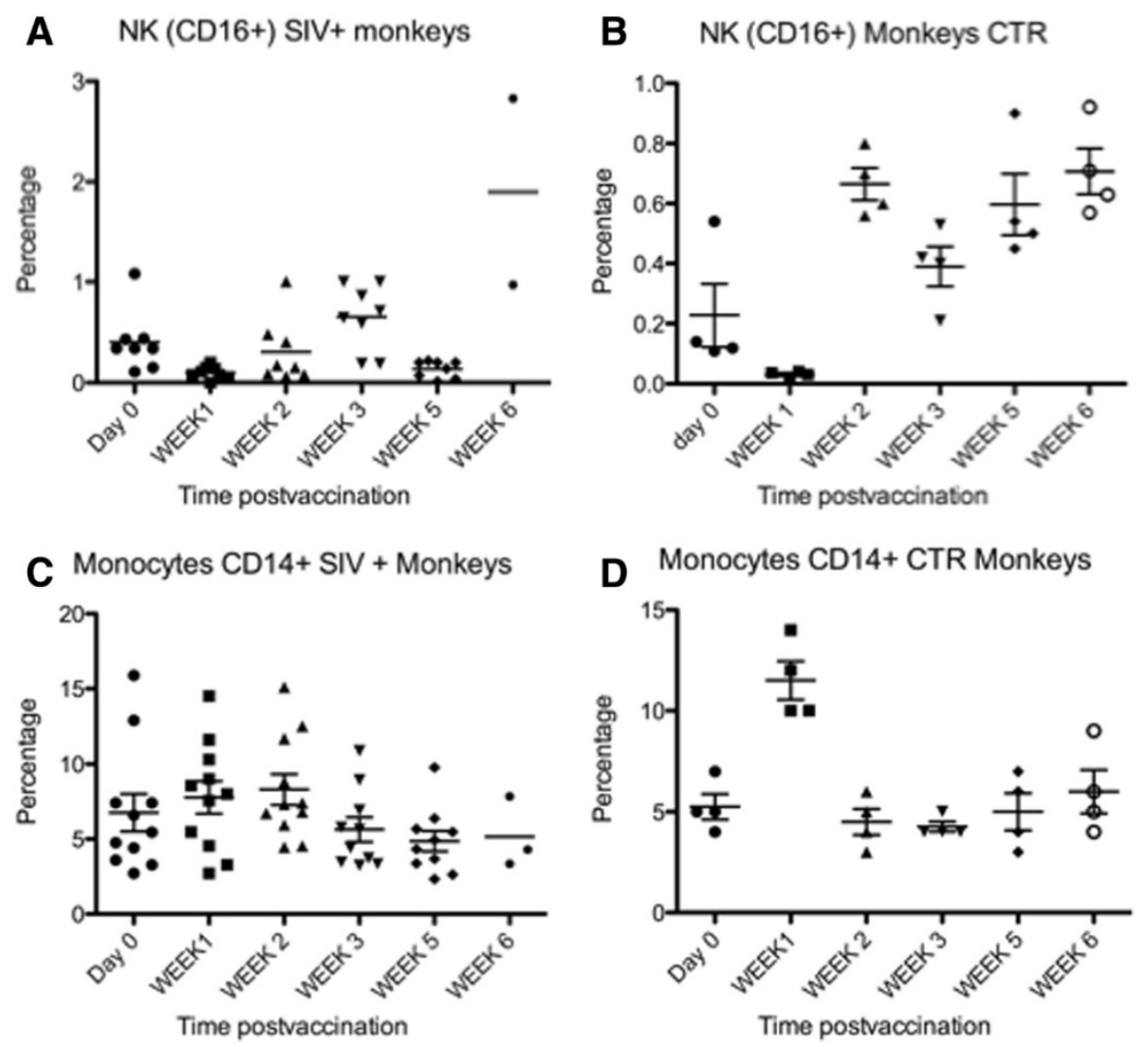

Figure 5 Percentage of monocytes and NK cells in PBMC after ML29 vaccination. A) In the 8 SIV-infected, ML29-vaccinated monkeys there is a significant reduction of the percentage of circulating NK (CD16+) cells one week after vaccination. B) Reduction of the NK (CD16+) population in four healthy (non-SIV-infected) animals one week after ML29 vaccination. C) In the 11 SIV-infected, arenavirus-vaccinated monkeys there is a slight increase in monocytes a week after ML29 vaccination. D) This increase is also observed in non-SIV-infected control monkeys. 


\begin{tabular}{|c|c|c|c|c|}
\hline Gene & $\begin{array}{l}\text { Fold Change } \\
\text { from Uninf } \\
\text { Week } 1\end{array}$ & $\begin{array}{l}\text { Fold Change } \\
\text { from SIV-inf } \\
\text { Week } 1\end{array}$ & $\begin{array}{l}\text { Virulent (WE } \\
\text { Week } 1\end{array}$ & ) vs ARM \\
\hline OAS1 & 1.0 & $-3.37 \square$ & 15 & \\
\hline IFI27 & $46 \square$ & 2.89 & 37 & \\
\hline SERPIN B1 & -2.18 & 2.04 & 23 & \\
\hline IL-1B & 75.89 & 87.34 & -6 & \\
\hline NR4A2 & -1.4 & 1.2 & -17 & \\
\hline PTGS2 & 2.43 & 2.27 & -60 to -300 & \\
\hline IL-8 & 2.35 & $-4.3,3.36$ & -11 & \\
\hline CXCL10 & 26 & 24 & 49.6 & \\
\hline
\end{tabular}

Figure 6 Gene expression of SIV-infected monkeys given the ML29 Lassa vaccine. Column one has the Genbank gene name. Column two has the fold difference in gene expression between ML29-vaccinated and uninfected (no SIV) monkeys, week 1. Column three has the fold difference in gene expression between ML29-vaccinated and SIV-infected, week 1. Column four has week one gene expression data from our previous profiling of monkeys inoculated with virulent and non-virulent strains of LCMV [35]. The blue star indicates indicates potential virulence markers in primate and guinea pig infections with virulent/mild virus pairs.

SIV-infection resulted in more detectable ML29 virus than has been seen in uninfected macaques. In our previous studies with ML29-vaccinated macaques, no infectious ML29 virus could be detected in urine or plasma but traces of virus could be detected in lymphoid tissues only during the first two weeks after vaccination using sensitive two-step amplification techniques [10]. With ML29vaccinated marmosets, only transient viremia was detected in 3 out of 16 animals by the two-step virus amplification technique, and viral nucleic acids could be detected in urine, saliva and vaginal swabs from only one animal [11]. With the SIV-infected monkeys in this study, the two-step amplification assay detected live ML29 virus in 3 of 8 ML29-vaccinated monkeys. Of the four SIV/ ML29-monkeys still surviving after 20 weeks, two had experienced transient ML29 viremia and 2 had not; so the transient ML29 viremia did not have a measurable impact on health.

Next we determined whether the arenavirus ML29 established a chronic infection in the SIV-infected monkeys. In murine models of LCMV and LASV infection, immunological defects such as depleted CD4 or CD8+ T cells often resulted in viral persistence [41,42]. Arenavirus persistence is unusual in primates but long-term shedding of LASV has been observed [3], and high IgM titers against LASV antigens persist for months in Lassa patients [43]. In the case of SIV-infected monkeys, one might expect that an ordinarily transient ML29 infection could persist in the context of immunodeficiency. Monkey urine and plasma were monitored weekly, and ML29 virus was not detectable by five weeks after vaccination. Thus, the SIV-infection did not mediate any detectable virus persistence.

Classical signs of arenavirus disease include virus crossing the blood-brain-barrier, high liver enzyme levels in plasma, and petechiae. Virus was not detectable in brain tissue of any ML29 animals examined after necropsy. None of our ML29-vaccinated animals developed high levels of AST, ALT, or bilirubin, whereas in Lassa fever and in lethal LCMV-WE infection, AST greater than $150 \mathrm{IU} / \mathrm{ml}$ plasma indicates poor prognosis $[39,40,44]$. Petechiae typical of virulent arenavirus disease were not observed during daily monitoring of the ML29-vaccinated animals. Thus, ML29 did not become virulent in the context of SIV infection.

Non-classical signs of virulence were sought by transcriptome profiling of monkey PBMC-derived RNA. In our previous studies, extensive transcriptome profiles of rhesus macaques with virulent and mild arenavirus infections revealed gene expression that distinguished arenavirus infection from no infection, and gene expression that distinguished virulent infection from mild infection $[35,45]$. Transcriptome profiling of the SIVinfected rhesus macaques in this study indicated that all the animals were infected with an arenavirus, and none of them had gene-expression patterns consistent with virulent arenavirus infection. Comparison of data from SIV-infected cohorts with data from SIV/ML29infected cohorts revealed differential expression of specific pathways, including the cyclo-oxygenase/prostaglandin (PTGS2) pathway, the Serpin B-related coagulation pathway, the nuclear-receptor 4 signaling pathway, interferon-stimulated genes (ISG) like OAS and IFI27, and the IL-8/IP-10 chemokines. Studies described here were consistent with the observation that SIV/ML29-infected animals did not display signs of gene expression previously associated with virulent arenavirus infections.

A second goal of our studies was to determine whether SIV/ML29-infected animals could elicit immune responses comparable to those seen in animals given ML29 alone. All but one of the 11 SIV-infected, arenavirus-infected animals elicited measurable cellmediated and humoral immune responses and the levels were similar to those in the non-SIV-infected cohort. The one animal with no measurable immunity was a 
median AIDS progressor that lived until 19 weeks after ML29 vaccination when he succumbed to AIDS. Cellmediated responses were variable in the SIV-infected cohorts but comparable to the ML29-alone cohorts, and ML29-specific antibody responses were frequently better in SIV-infected monkeys than in the non-SIV-infected monkeys. In a study conducted in LASV-infected cynomolgus monkeys [5] LASV-specific IgG responses were detected 12 days after challenge, with higher titers in survivors than in fatal cases. This suggests that the humoral response is induced earlier and more strongly in nonfatal infections [5]. We failed to observe a correlation between ML29 titers and survival, probably because survival in our study was due to AIDS progression and not related to the arenavirus infection.

Several other studies have used non-human primate AIDS models to explore the safety and efficacy of vaccines. In one study, SHIV-infected rhesus macaques were given a vesicular stomatitis virus-based ebola vaccine and all six vaccinees survived a lethal ebola challenge [17]. In another study SIVmac251-infected rhesus macaques were vaccinated against smallpox: those with low CD4 counts failed to elicit neutralizing antibodies and succumbed to lethal monkeypox challenge, whereas those with normal CD4 counts elicited neutralizing antibody and survived a lethal challenge [18].

In our study all the monkeys maintained normal CD4 counts but exhibited other signs of AIDS including SIVviremia, wasting and lymphadenopathy. In fact 5 of the 16 SIV-infected monkeys scheduled for ML29 vaccination died of AIDS before they could be vaccinated. Attrition of the remaining 11 animals continued at a rate expected for death from AIDS alone; all dying macaques showed signs of AIDS rather than signs of arenavirus disease.

By the end of our study, 5 monkeys remained healthy without developing classical or non-classical signs of virulent arenavirus disease.

\section{Conclusions}

SIV-infected macaques given the attenuated Lassa vaccine ML29 did not show increased signs of arenavirus disease or shortened lifespan. A slight increase in ML29 viremia in SIV-infected as compared to non-SIV-infected macaques was noted. No increased shedding or persistence of ML29 was noted in the SIV-infected hosts. ML29 elicits cell-mediated and humoral immune responses to LASV similarly in SIV-infected and nonSIV-infected animals.

\section{Materials and methods Viruses and cells}

Mopeia/Lassa reassortant virus (clone ML29) was previously tested as a vaccine against Lassa fever [10,26,27].
Vero E6 cells (\#CRL-1586, ATCC) were cultured in Dulbeccos's modified Eagle's medium (DMEM, GIBCO-BRL) supplemented with $10 \%$ fetal bovine serum (FBS, GIBCOBLR), $1 \%$ penicillin-streptomycin, and $2 \mathrm{mM}$ L-glutamine. To produce the ML29 inoculum, Vero cell monolayers were infected with ML29 master stock at a multiplicity of infection (MOI) of 0.01 and incubated 1 hour at $37^{\circ} \mathrm{C}$ in $5 \% \mathrm{CO}_{2}$, then washed with PBS and covered in DMEM $2 \%$ FBS. Supernatants were collected at 48 and 72 hours after infection, stored at $-70^{\circ} \mathrm{C}$, and titrated on Vero cells. Supernatants usually had about $10^{7}$ plaque forming units (pfu)/ml. Stocks of lymphocytic choriomeningitis virusArmstrong (LCMV-ARM) and LCMV-WE (described extensively in [44]) were similarly produced and titrated on Vero E6 cells and stored at $-70^{\circ} \mathrm{C}$.

SIVmac251 (originally supplied by Ron Desrosiers) was amplified on rhesus macaque PBMC and given a final passage on CEMX174 cells as described [46]. Monkeys were infected by inoculating 10 TCID50 per animal by the saphenous vein.

Whole blood collected in heparin was used to stain for cell surface and intracellular markers (especially for cellmediated immunity assays). Fresh monkey PBMC for transcriptome analyses were obtained from $10 \mathrm{ml}$ of heparin blood by Ficoll-hypaque isolation [47] and resuspended in RPMI medium 1640 with 10\% FBS (Sigma) for RNA extraction as described below [35]. Residual PBMC were frozen at $-140^{\circ} \mathrm{C}$ at a concentration of $10^{7}$ cells $/ \mathrm{ml}$. Upon necropsy, splenocytes were obtained for cellmediated immunity assays: fresh tissue pieces were pressed through mesh, exposed to red cell lysis buffer 5 minutes, then suspended in freezing media and stored at $-140^{\circ} \mathrm{C}$ at a concentration of $10^{7}$ cells $/ \mathrm{ml}$. Serum samples and plasma samples were stored at $-140^{\circ} \mathrm{C}$ before being analyzed for virus or antibody content.

\section{Animals and immunization}

Rhesus macaques (Rh) were purchased from the Caribbean Primate Colony. Experimental protocols were approved by the Institutional Animal Care and Use Committee at the University of Maryland School of Medicine. Of 16 monkeys inoculated with SIVmac251 as previously described [19], 5 were dying with symptoms of SIV disease and had to be euthanized almost a year after SIV infection and before the onset of the ML29 vaccinations. Of the remaining 11 animals, 8 were inoculated with the ML29 vaccine candidate and 3 were inoculated with LCMV-Armstrong, known to be benign in AIDS monkeys (Salvato MS and Zapata JC, not shown). Of the 8 ML29-vaccinees, 5 were inoculated s.c. with $0.5 \mathrm{ml} 10^{3}$ pfu ML29 and 3 were inoculated i..g. with $2 \mathrm{ml} 10^{6} \mathrm{pfu}$ ML29. In addition, 5 healthy control animals were vaccinated s.c. with $0.5 \mathrm{ml}$ of ML29 containing $10^{3} \mathrm{pfu}$. Blood was collected every week for flow cytometry, viral loads, antibody detection, clinical 
chemistry, hematology, and transcriptome profiles as described [35]. Six weeks after their first vaccination, 6 macaques (ML-1, SIV/ML-1, SIV/ML-2, SIV/ML-6, SIV/ ML-7, SIV/ARM-1) were boosted s.c. with $10^{3}$ pfu ML29. Animals were monitored daily for weight loss, rashes and clinical signs of SIV or arenavirus disease.

For weight loss over $10 \%$ of body weight and in consultation with the veterinary staff, monkeys were euthanized and total blood and tissues [lung, spleen, mesenteric lymph nodes (LN), liver, stomach, ileum, kidney, heart, cerebrum, and cerebellum] were collected. A portion of each tissue was submerged in MEM with $10 \%$ FCS for virus and RNA isolation. The remaining tissue portions were flash frozen in liquid nitrogen to be used in virus isolation or fixed in $10 \%$ neutral formalin for the preparation of histological sections. Also, at the end of the study surviving healthy animals were euthanized and blood and tissues collected.

\section{Detection of SIV and arenavirus in monkey tissues}

SIV viral loads were evaluated from plasma samples using real-time NASBA to determine the number of RNA copies per milliliter (Advanced Biosciences Laboratory, Kensington, MD). This technique can detect 100 SIV RNA copies per ml plasma. Based on SIV-infected animal set points $[48,49]$, monkeys were considered slow AIDS progressors $\left(<10^{4}\right.$ RNA molecules $\left./ \mathrm{ml}\right)$, median progressors $\left(10^{4}\right.$ to $10^{6}$ RNA molecules $\left./ \mathrm{ml}\right)$, and rapid progressors ( $>10^{6}$ RNA molecules $/ \mathrm{ml}$ ). Of the eight SIV-infected animals inoculated with ML29, two were slow progressors (SIV/ML-2, SIV/ML-5), 5 were median progressors (SIV/ ML-1, SIV/ML-4, SIV/ML-6, SIV/ML7, and SIV/ML-8) and one was a rapid progressor (SIV/ML-3). Of the three monkeys inoculated with the mild LCMV-ARM, one was a slow progressor (SIV/ARM -2) and two were rapid progressors (SIV/ARM -1 and SIV/ARM -3).

Arenaviruses were detected by three different methods: 1) conventional plaque assays that are sensitive to 20 infectious particles in $1 \mathrm{ml}$ solution and were used for assessments of plasma or tissue viremia for arenaviruses ML29, LCMV-Armstrong, and LCMV-WE [11]; 2) RTPCR that detects 10 viral genomes in $200 \mu \mathrm{l}$ serum and was used in all tissues samples (as described in [11]; and 3) a sensitive 2-step amplification assay in which infected plasma or cells are co-cultivated with Vero cells one week, then the media is subjected to plaque assay. The 2-step assay increases the plaque detection up to 1 infectious particle per $\mathrm{ml}[10,11]$.

\section{Flow cytometry to characterize PBMC}

Ten $\mathrm{ml}$ of whole blood was collected in heparin tubes, and $100 \mu \mathrm{l}$ was mixed with each antibody panel (mixtures of fluorochrome-conjugated antibodies supplied by BD Bioscience San Jose, CA). Panel 1 included mouse anti-human CD20-FITC (clone 2H7), CD3-PE (clone SP34-2), CD4-APC (clone L200), and CD8-PerCP (clone SK1) to detect B and T lymphocyte populations. Panel 2 included mouse anti-human CD16-FITC (clone 3 G8), CD56-PE (clone NCAM16.2), CD4-APC (clone L200), and CD8-PerCP (clone SK1) to detect NK, gamma-delta T cell $(\gamma \delta$ T cell), and NKT cell populations. Panel 3 included CD14-FITC (clone M5E2) and CD4-APC (clone L200), to detect monocyte and $\mathrm{T}$ cell populations. Panel 4 included CD3-PE, and TCR Vgamma9-FITC (clone IMMU 360, Beckman Coulter). After 30 min, FACS Lysing Solution (BD) was added for red cell lysis and incubated $20 \mathrm{~min}$ at room temperature. Cells were washed twice with PBS and fixed in $2 \%$ formaldehyde, then collected in a FACScalibur (BD) and data were analyzed with FlowJo Software (Tree Star, San Carlos, CA).

\section{Intracellular staining for virus-specific IFNy responses}

Whole heparinized blood $(0.5 \mathrm{ml})$ was stimulated with $<50 \mu \mathrm{l}$ of ML29 $\left(5 \times 10^{5} \mathrm{pfu}\right)$ or MEM (control) at $37^{\circ} \mathrm{C}$, $5 \% \mathrm{CO}_{2}$ overnight. $25 \mu \mathrm{l}$ of 1:10 dilution of monensin (Golgiplug, BD) was added to each sample 4 hours prior to staining. Then cells were stained for surface antigens with anti-CD4-APC (clone L200) and CD8 (clone SK1) and stained for intracellular IFNy using monoclonal antibody 4S.B3 and the Cytofix Cytoperm kit (BD). Samples were analyzed on a FACSCalibur instrument with 50,000 events in the lymphocyte gate and results were analyzed using FlowJo software (TreeStar).

\section{IFNy ELISPOT}

PBMC from immunized animals were used in IFNy ELISPOT (U-CyTech B.V., Ultrecht, The Netherlands) according to the manufacturer's recommendations with slight modifications [10]. Briefly, $2 \times 10^{6}$ cells in $0.5 \mathrm{ml}$ of RPMI1640 (Invitrogen) with 5\% FBS, $2 \mathrm{mM}$ glutamine, 100 units $/ \mathrm{ml}$ penicillin, $100 \mu \mathrm{g} / \mathrm{ml}$ streptomycin, and $25 \mathrm{mM}$ Hepes buffer were stimulated by co-incubation overnight at $37^{\circ} \mathrm{C}$ with $2 \times 10^{6}$ pfu of ML29. After stimulation, the cells were washed, resuspended in the same medium, and $0.3-0.4 \times 10^{6}$ cells/well were added to ELISPOT 96-well plates pre-coated with mouse anti-monkey IFN $\gamma$. The plates were incubated at $37^{\circ} \mathrm{C}$ for $5 \mathrm{~h}$, washed, and incubated with gold-conjugated anti-biotin. The spot-forming cells (SFC) secreting IFNy were developed with activator solution and counted (Immunospot 3.2 Analyzer, C.T.L. Cellular Tech., Ltd.)

\section{ELISA}

Anti-LAS-GPC antibodies in serum samples were measured by IgG ELISA as previously described [10]. Supernatants of ML29-infected Vero E6 cells were concentrated in $15 \mathrm{ml}$ Amicon tubes then sonicated using a Misonix-S4000 sonicator (MISONIX, Newtown, CT). This concentrated- 
antigen was suspended in carbonate-bicarbonate buffer (pH 9.6), and $100 \mu \mathrm{l}$ of antigen was adsorbed to the wells of microtitration plates overnight at $4{ }^{\circ} \mathrm{C}$. After washing the 96-well plates 6 times with PBS-Tween $(0.05 \%)$, two-fold dilutions (1/50 to $1 / 400)$ of plasma were added and incubated for an hour at $37^{\circ} \mathrm{C}$. Wells were washed 5 times, and $100 \mu \mathrm{l}$ of 5,000-times diluted peroxidase-conjugated goat anti-monkey IgG (A-2054, Sigma) was added and incubated one hr, then washed 6 times, then substrates were added, incubated for $30 \mathrm{~min}$ in the dark, then stopped with $100 \mu \mathrm{l} /$ well of $1 \mathrm{M}$ phosphoric acid and read at $\mathrm{OD}_{450}$ on a Wallac 1420 plate-reading spectrophotometer.

\section{Gene expression from monkey PBMC CDNA}

Total RNA was isolated from fresh PMBC samples, using the Trizol method (Invitrogen, Carlsbad, CA) followed by a cleaning step with RNeasy mini kit (Qiagen, Valencia, CA). Quality and quantity of all RNA samples were evaluated on an Agilent 2100 BioAnalyzer 116 (Agilent Technologies, Palo Alto, CA) by looking at 18 and $28 \mathrm{~s}$ rRNA peaks and by the RIN (RNA integrity number). High quality RNA was labeled and hybridized according to Affymetrix protocols using the human GeneChip U133 Plus 2.0 array (Affymetrix, Santa Clara, CA) as described previously [45]. This chip covers the whole human genome using 54,000 probesets representing approximately 22,000 genes and has been validated for use with non-human primates [50-52]. Although many PBMC-RNA samples were analyzed, the only ones from sufficiently large groups to yield statistically significant data were the SIV-infected samples $(n=8)$, the SIV/ ML29 s.c. week 1 samples $(n=5)$ and the SIV/ML29 s.c. week 2 samples $(n=5)$. Smaller groups included SIV/ ML29 i.g. weeks 1 and 2, SIV/LCM s.c. weeks 1 and 2, ML29 i.v. weeks 1 and 2 and the uninfected samples.

\section{Abbreviations}

SIV: Simian immunodeficiency virus; ML29: Mopeia Lassa reassortant isolate 29; LASV: Lassa virus; LCMV: Lymphocytic choriomeningitis virus (including strains LCMV-Armstrong and LCMV-WE); Pfu: Plaque forming units for arenavirus titers; IFNy: Interferon-gamma; s.c: Subcutaneous; i.g: Intragastric; i. v: Intravenous; LN: Lymph nodes; NASBA: Nucleic Acid Sequence Based Assays; RT-PCR: Reverse transcription followed by polymerase chain reaction.

\section{Competing interests}

The authors declare that they have no competing interest.

\section{Authors' contributions}

JCZ coordinated this work, carried out laboratory experiments, data analysis and drafted the manuscript; $B P, J B, H D, E A$, and LG did all animal vaccinations, sample collections and reviewed the manuscript; JCZ, TS, and $\mathrm{CJ}$, participated in virus identification from urine samples; $\mathrm{OC}$ and $\mathrm{YZ}$ performed the microarray analyses of monkey PBMC RNA; MG and JCZ did immune assays; DM and JCZ detected gene expression and genetic integration of ML29; CDP provided animals and helped to draft the manuscript; ISL, helped to interpret results; MSS conceived, designed and helped to draft the manuscript. All authors read and approved the final manuscript.

\section{Acknowledgements}

Besides co-authors TS and CJ, their team at Lawrence Livermore Laboratory contributed to the identification of viruses in monkey blood and urine using Lawrence Livermore Microbial Detection Arrays. The team included James Thissen who performed microarray experiments, Kevin McLoughlin and Pauline Gu who performed statistical analysis, and Shea Gardner who contributed microarray probe design. Their work was supported by Laboratory Directed Research and Development grant number 08-SI-002 from Lawrence Livermore National Laboratory https://www.Inl.gov/ and the National Biodefense Analysis and Countermeasures Center http://www.dhs. gov/national-biodefense-analysis-and-countermeasures-center award number L164212/F0901.

Funding for transcriptome analysis of monkey PBMC was from a subcontract from the Mid-Atlantic Regional Centers of Excellence and Emerging Infectious Disease Research [MARCE; U54 Al057168 to M. Levine]. The bioinformatics data analysis at VBI was funded by Department of Defense grant DAAD 13-02-C-0018 to B. Sobral. Funding for the experiments with primates was provided by National Institute of Health grants to M Salvato (Al074790), to IS Lukashevich (Al052367 and Al068961), and to C. David Pauza (Al068508).

\section{Author details}

'Institute of Human Virology, University of Maryland School of Medicine, 725 West Lombard Street, Baltimore, MD 21201, USA. ${ }^{2}$ Virginia Bioinformatics Institute at Virginia Tech, Blacksburg, VA 24061, USA. ${ }^{3}$ Global Security Directorate, Lawrence Livermore National Laboratory, 7000 East Ave, Livermore, CA 94550, USA. ${ }^{4} \mathrm{New}$ address for ISL: NIH National Regional Biocontainment Laboratory, 950 N Hurstbourne Pkwy, Louisville, KY 40222, USA.

Received: 9 July 2012 Accepted: 28 January 2013

Published: 12 February 2013

\section{References}

1. Fisher-Hoch SP, McCormick JB: Pathophysiology and treatment of Lassa fever. Curr Top Microbiol Immunol 1987, 134:231-239.

2. Fisher-Hoch SP, Tomori O, Nasidi A, Perez-Oronoz Gl, Fakile Y, Hutwagner L, McCormick JB: Review of cases of nosocomial Lassa fever in Nigeria: the high price of poor medical practice. BMJ 1995, 311:857-859.

3. Johnson KM, McCormick JB, Webb PA, Smith ES, Elliott LH, King IJ: Clinical virology of Lassa fever in hospitalized patients. J Infect Dis 1987, 155:456-464.

4. Baize S, Leroy EM, Georges-Courbot MC, Capron M, Lansoud-Soukate J, Debre P, Fisher-Hoch SP, McCormick JB, Georges AJ: Defective humoral responses and extensive intravascular apoptosis are associated with fatal outcome in Ebola virus-infected patients. Nat Med 1999, 5:423-426.

5. Baize S, Marianneau P, Loth P, Reynard S, Journeaux A, Chevallier M, Tordo $\mathrm{N}$, Deubel $\mathrm{V}$, Contamin H: Early and strong immune responses are associated with control of viral replication and recovery in lassa virusinfected cynomolgus monkeys. J Virol 2009, 83:5890-5903.

6. McCormick JB, Walker DH, King IJ, Webb PA, Elliott LH, Whitfield SG, Johnson KM: Lassa virus hepatitis: a study of fatal Lassa fever in humans. Am J Trop Med Hyg 1986, 35:401-407.

7. Salvato MS, Lukashevich IS: Vaccines against Lassa Fever. New York: Marcel Dekker, Inc; 2009.

8. Fisher-Hoch SP, McCormick JB, Auperin D, Brown BG, Castor M, Perez G, Ruo S, Conaty A, Brammer L, Bauer S: Protection of rhesus monkeys from fatal Lassa fever by vaccination with a recombinant vaccinia virus containing the Lassa virus glycoprotein gene. Proc Natl Acad Sci USA 1989, 86:317-321.

9. Geisbert TW, Jones S, Fritz EA, Shurtleff AC, Geisbert JB, Liebscher R, Grolla A, Stroher U, Fernando L, Daddario KM, et al: Development of a new vaccine for the prevention of Lassa fever. PLoS Med 2005, 2:e183.

10. Lukashevich IS, Patterson J, Carrion R, Moshkoff D, Ticer A, Zapata J, Brasky K, Geiger R, Hubbard GB, Bryant J, Salvato MS: A live attenuated vaccine for Lassa fever made by reassortment of Lassa and Mopeia viruses. J Virol 2005, 79:13934-13942.

11. Lukashevich IS, Carrion R Jr, Salvato MS, Mansfield K, Brasky K, Zapata J, Cairo C, Goicochea M, Hoosien GE, Ticer A, et al: Safety, immunogenicity, and efficacy of the ML29 reassortant vaccine for Lassa fever in small non-human primates. Vaccine 2008, 26:5246-5254.

12. Carrion R Jr, Brasky K, Mansfield K, Johnson C, Gonzales M, Ticer A, Lukashevich I, Tardif S, Patterson J: Lassa virus infection in experimentally 
infected marmosets: liver pathology and immunophenotypic alterations in target tissues. J Virol 2007, 81:6482-6490.

13. Lukashevich IS: Advanced Vaccine Candidates for Lassa Fever". Viruses 2013, 4:2514-2557.

14. Bredenbeek PJ, Molenkamp R, Spaan WJ, Deubel V, Marianneau P, Salvato MS, Moshkoff D, Zapata J, Tikhonov I, Patterson J, et al: A recombinant Yellow Fever 17D vaccine expressing Lassa virus glycoproteins. Virology 2006, 345:299-304

15. Aina O, Dadik J, Charurat M, Amangaman P, Gurumdi S, Mang E, Guyit R, Lar N, Datong P, Daniyam C, et al: Reference values of CD4 T lymphocytes in human immunodeficiency virus-negative adult Nigerians. Clin Diagn Lab Immunol 2005, 12:525-530

16. Papin JF, Verardi PH, Jones LA, Monge-Navarro F, Brault AC, Holbrook MR, Worthy MN, Freiberg AN, Yilma TD: Recombinant Rift Valley fever vaccines induce protective levels of antibody in baboons and resistance to lethal challenge in mice. Proc Natl Acad Sci USA 2011, 108:14926-14931.

17. Geisbert TW, Daddario-Dicaprio KM, Lewis MG, Geisbert JB, Grolla A, Leung A, Paragas J, Matthias L, Smith MA, Jones SM, et al: Vesicular stomatitis virusbased ebola vaccine is well-tolerated and protects immunocompromised nonhuman primates. PLoS Pathog 2008, 4:1000225.

18. Edghill-Smith Y, Bray M, Whitehouse CA, Miller D, Mucker E, Manischewitz J, King LR, Robert-Guroff M, Hryniewicz A, Venzon D, et al: Smallpox vaccine does not protect macaques with AIDS from a lethal monkeypox virus challenge. J Infect Dis 2005, 191:372-381.

19. Poonia B, Salvato MS, Yagita H, Maeda T, Okumura K, Pauza CD: Treatment with anti-FasL antibody preserves memory lymphocytes and virusspecific cellular immunity in macaques challenged with simian immunodeficiency virus. Blood 2009, 114:1 196-1204.

20. Carrion R Jr, Patterson JL, Johnson C, Gonzales M, Moreira CR, Ticer A, Brasky K, Hubbard GB, Moshkoff D, Zapata J, et al: A ML29 reassortant virus protects guinea pigs against a distantly related Nigerian strain of Lassa virus and can provide sterilizing immunity. Vaccine 2007, 25:4093-4102.

21. Goicochea MA, Zapata JC, Bryant J, Davis H, Salvato MS, Lukashevich IS: Evaluation of Lassa virus vaccine immunogenicity in a CBA/J-ML29 mouse model. Vaccine 2012, 30:1445-1452.

22. Kiley MP, Lange JV, Johnson KM: Protection of rhesus monkeys from Lassa virus by immunisation with closely related Arenavirus. Lancet 1979, 2:738.

23. Peters CJ, Jahrling PB, Liu CT, Kenyon RH, McKee KT Jr, Barrera Oro JG: Experimental studies of arenaviral hemorrhagic fevers. Curr Top Microbiol Immunol 1987, 134:5-68.

24. McCormick JB: Epidemiology and control of Lassa fever. Curr Top Microbiol Immunol 1987, 134:69-78.

25. Borremans B, Leirs H, Gryseels S, Gunther S, Makundi R, de Bellocq JG: Presence of Mopeia virus, an African arenavirus, related to biotope and individual rodent host characteristics: implications for virus transmission. Vector Borne Zoonotic Dis 2011, 11:1125-1131.

26. Lukashevich IS: Generation of reassortants between African arenaviruses. Virology 1992, 188:600-605.

27. Moshkoff DA, Salvato MS, Lukashevich IS: Molecular characterization of a reassortant virus derived from Lassa and Mopeia viruses. Virus Genes 2007, 34:169-176.

28. Rodas JD, Lukashevich IS, Zapata JC, Cairo C, Tikhonov I, Djavani M, Pauza $C D$, Salvato MS: Mucosal arenavirus infection of primates can protect them from lethal hemorrhagic fever. J Med Virol 2004, 72:424-435.

29. Gardner SN, Jaing CJ, McLoughlin KS, Slezak TR: A microbial detection array (MDA) for viral and bacterial detection. BMC Genomics 2010, 11:668.

30. Jones MS, Harrach B, Ganac RD, Gozum MM, Dela Cruz WP, Riedel B, Pan C, Delwart EL, Schnurr DP: New adenovirus species found in a patient presenting with gastroenteritis. J Virol 81, 81:5978-5984.

31. Banyai K, Martella V, Meleg E, Kisfali P, Peterfi Z, Benko M, Melegh B, Szucs G: Searching for HAdV-52, the putative gastroenteritis-associated human adenovirus serotype in Southern Hungary. New Microbiol 2009, 32:185-188.

32. Roy S, Vandenberghe LH, Kryazhimskiy S, Grant R, Calcedo R, Yuan X, Keough M, Sandhu A, Wang Q, Medina-Jaszek CA, et al: Isolation and characterization of adenoviruses persistently shed from the gastrointestinal tract of nonhuman primates. PLoS Pathog 2009, 5:e1000503.

33. Scharko AM, Perlman SB, Hinds PW, Hanson JM, Uno H, Pauza CD: Whole body positron emission tomography imaging of simian immunodeficiency virus-infected rhesus macaques. Proc Natl Acad Sci USA 1996, 93:6425-6430.

34. Rodas JD, Cairo C, Djavani M, Zapata JC, Ruckwardt T, Bryant J, Pauza CD Lukashevich IS, Salvato MS: Circulating natural killer and gammadelta T cells decrease soon after infection of rhesus macaques with lymphocytic choriomeningitis virus. Mem Inst Oswaldo Cruz 2009, 104:583-591.

35. Djavani MM, Crasta OR, Zapata JC, Fei Z, Folkerts O, Sobral B, Swindells M, Bryant J, Davis $H$, Pauza CD, et al: Early blood profiles of virus infection in a monkey model for Lassa fever. J Virol 2007, 81:7960-7973.

36. Bowick GC, Fennewald SM, Scott EP, Zhang L, Elsom BL, Aronson JF, Spratt HM, Luxon BA, Gorenstein DG, Herzog NK: Identification of differentially activated cell-signaling networks associated with pichinde virus pathogenesis by using systems kinomics. J Virol 2007, 81:1923-1933.

37. Bowick GC, Fennewald SM, Zhang L, Yang X, Aronson JF, Shope RE, Luxon BA, Gorenstein DG, Herzog NK: Attenuated and lethal variants of Pichinde virus induce differential patterns of NF-kappaB activation suggesting a potential target for novel therapeutics. Viral Immunol 2009, 22:457-462.

38. Fennewald SM, Scott EP, Zhang L, Yang X, Aronson JF, Gorenstein DG, Luxon BA, Shope RE, Beasley DW, Barrett AD, Herzog NK: Thioaptamer decoy targeting of AP-1 proteins influences cytokine expression and the outcome of arenavirus infections. J Gen Virol 2007, 88:981-990

39. McCormick JB, Fisher-Hoch SP: Lassa fever. Curr Top Microbiol Immunol 2002, 262:75-109.

40. Lukashevich IS, Tikhonov I, Rodas JD, Zapata JC, Yang Y, Djavani M, Salvato MS: Arenavirus-mediated liver pathology: acute lymphocytic choriomeningitis virus infection of rhesus macaques is characterized by high-level interleukin6 expression and hepatocyte proliferation. J Virol 2003, 77:1727-1737.

41. Matloubian M, Concepcion RJ, Ahmed R: CD4+ T cells are required to sustain CD8+ cytotoxic T-cell responses during chronic viral infection. J Virol 1994, 68:8056-8063.

42. Flatz L, Rieger T, Merkler D, Bergthaler A, Regen T, Schedensack M, Bestmann L, Verschoor A, Kreutzfeldt M, Bruck W, et al: T cell-dependence of Lassa fever pathogenesis. PLoS Pathog 2010, 6:e1000836.

43. Grove JN, Branco LM, Boisen ML, Muncy IJ, Henderson LA, Schieffellin JS, Robinson JE, Bangura JJ, Fonnie M, Schoepp RJ, et al: Capacity building permitting comprehensive monitoring of a severe case of Lassa hemorrhagic fever in Sierra Leone with a positive outcome: case report. Virol J 2011, 8:314

44. Lukashevich IS, Djavani M, Rodas JD, Zapata JC, Usborne A, Emerson C, Mitchen J, Jahrling PB, Salvato MS: Hemorrhagic fever occurs after intravenous, but not after intragastric, inoculation of rhesus macaques with lymphocytic choriomeningitis virus. J Med Virol 2002, 67:171-186.

45. Djavani M, Crasta OR, Zhang Y, Zapata JC, Sobral B, Lechner MG, Bryant J, Davis H, Salvato MS: Gene expression in primate liver during viral hemorrhagic fever. Virol J 2009, 6:20.

46. Trivedi P, Meyer KK, Streblow DN, Preuninger BL, Schultz KT, Pauza CD: Selective amplification of simian immunodeficiency virus genotypes after intrarectal inoculation of rhesus monkeys. J Virol 1994, 68:7649-7653.

47. Tripodi D, Lyons S, Davies D: Separation of peripheral leukocytes by Ficoll density gradient centrifugation. Transplantation 1971, 11:487-488.

48. Dykhuizen M, Mitchen JL, Montefiori DC, Thomson J, Acker L, Lardy H, Pauza CD: Determinants of disease in the simian immunodeficiency virus-infected rhesus macaque: characterizing animals with low antibody responses and rapid progression. J Gen Virol 1998, 79(Pt 10):2461-2467.

49. Mellors JW, Rinaldo CR Jr, Gupta P, White RM, Todd JA, Kingsley LA: Prognosis in HIV-1 infection predicted by the quantity of virus in plasma. Science 1996, 272:1167-1170.

50. Ace Cl, Okulicz WC: Microarray profiling of progesterone-regulated endometrial genes during the rhesus monkey secretory phase. Reprod Biol Endocrinol 2004, 2:54

51. Rubins $K H$, Hensley LE, Jahrling PB, Whitney AR, Geisbert TW, Huggins JW, Owen A, Leduc JW, Brown PO, Relman DA: The host response to smallpox: analysis of the gene expression program in peripheral blood cells in a nonhuman primate model. Proc Natl Acad Sci USA 2004, 101:15190-15195.

52. Wang Z, Lewis MG, Nau ME, Arnold A, Vahey MT: Identification and utilization of inter-species conserved (ISC) probesets on Affymetrix human GeneChip platforms for the optimization of the assessment of expression patterns in non human primate (NHP) samples. BMC Bioinformatics 2004, 5:165.

\section{doi:10.1186/1743-422X-10-52}

Cite this article as: Zapata et al.: An attenuated Lassa vaccine in SIVinfected rhesus macaques does not persist or cause arenavirus disease but does elicit Lassa virus-specific immunity. Virology Journal 2013 10:52. 